\title{
Pengaruh Kehidupan Sosial Dan Ekonomi Keluarga Terhadap Pernikahan Dini Pada Tahun 2020
}

\author{
Danang Prio Utomo ${ }^{1}$, Muhamad Ali², Rini Aprianti ${ }^{3}$ \\ ${ }^{123}$ Prodi Pendidikan Ekonomi, FISE, Universitas Hamzanwadi, \\ email: danangirenk@gmail.com
}

Received: 13 Desember, 2020; Accepted: 23 Desember 2020; Published: 25 Desember, 2020

\begin{abstract}
Abstrak
Nusa tenggara Barat (NTB) tercatat sebagai provinsi dengan tingkat perkawinan muda (merariq kodek) yang cukup tinggi, terutama paling banyak terjadi di kabupaten Lombok Timur kemudian Lombok Utara. Banyak faktor yang menyebabkan terjadinya pernikahan dibawah usia diantaranya faktor karena rasa cinta, faktor ekonomi, faktor dijodohkan, putus sekolah, dan hamil diluar nikah. Tujuan dari penelitian ini adalah untuk menguji pengaruh kehidupan sosial dan ekonomi keluarga terhadap pernikahan dini. Metode yang digunakan yaitu metode kuantitatif dengan pendekatan deskriptif, pada umumnya ada 33 sampel (responden) tetapi setelah menggunakan tehnik perhitungan sampel dengan rumus slovin dapat ditarik responden sebanyak 30, responden terdiri dari berbagai latar umur menikah, pekerjaan yang berbeda - beda. Semua data diolah dengan analisis regresi berganda dengan melihat uji validitas, realibiltas, uji asumsi klasik (uji normalitas data, uji multikolinearitas, dan uji heterokedastisitas) dan pengujian hipotesis dengan uji $\mathrm{F}$ dan uji t.

Hasil penelitian ini menunjukkan bahwa adanya pengaruh dari kehidupan sosial dan ekonomi keluarga terhadap pernikahan dini. Hal tersebut ditunjukkan dengan hasil pengujian simultan F hitung Pernikahan Dini sebesar $(45,191)$ dengan tingkat probabilitas $(0,000)$ yang berarti secara bersama - sama Kehidupan Sosial dan Ekonomi Keluarga mempunyai andil dalam mempengaruhi Pernikahan Dini di dusun Penyenggir, Manggong dan Batu Gapit. 3).Dari uji signifikan juga terbukti jika masing - masing variabel independen juga berpengaruh signifikan terhadap variabel dependen. Variabel kehidupan sosial (X1) mempunyai pengaruh yang signifikan terhadap pernikahan dini didusun Penyenggir, Manggong dan Batu Gapit. Hal ini ditunjukkan dengan thitung (4,537) dengan $\mathrm{p}$ value (sig) 0,000 lebih kecil dari 0,05 , berarti kehidupan sosial mempunyai andil dalam mempengaruhi pernikahan dini di desa Sikur Barat. Variabel ekonomi keluarga (X2) juga mempunyai pengaruh yang signifikan terhadap pernikahan dini di desa Sikur Barat. Hal ini ditunjukkan dengan t hitung $(3,735)$ dengan nilai $\mathrm{p}$ value (sig) sebesar 0,001 berada dibawah 0,05 berarti ekonomi keluarga mempunyai andil dalam mempengaruhi pernikahan dini di dusun Penyenggir, Manggong dan Batu Gapit.
\end{abstract}

Kata Kunci: Kehidupan Sosial, Ekonomi Keluarga dan Pernikahan dini 


\begin{abstract}
West Nusa Tenggara (NTB) is recorded as a province with a fairly high rate of young marriage (merariq kodek), especially in East Lombok then North Lombok. Many factors cause underage marriages, including factors due to love, economic factors, matchmaking factors, dropping out of school, and pregnancy outside of marriage. The purpose of this study was to examine the influence of family social and economic life on early marriage. The method used is a quantitative method with a descriptive approach, in general there are 33 samples (respondents) but after using the sample calculation technique with the Slovin formula, 30 respondents can be drawn, the respondents consist of various backgrounds of married age, different occupations. All data were processed by multiple regression analysis by looking at the validity test, reliability, classical assumption test (data normality test, multicollinearity test, and heteroscedasticity test) and hypothesis testing using the F test and $t$ test.

The results of this study indicate that there is an influence of family social and economic life on early marriage. This is indicated by the simultaneous test results of F count of Early Marriage at (45.191) with a probability level (0.000) which means that together the Social and Economic Life of the Family has a share in influencing Early Marriage in the hamlets of Penyenggir, Manggong and Batu Gapit. 3) From the significant test it is also proven that each independent variable also has a significant effect on the dependent variable. Social life variable (X1) has a significant influence on early marriage in the villages of Penyenggir, Manggong and Batu Gapit. This is indicated by t count (4.537) with p value (sig) 0.000 smaller than 0.05 , meaning that social life has a role in influencing early marriage in the village of West Sikur. The family economic variable (X2) also has a significant effect on early marriage in the village of West Sikur. This is indicated by t count (3.735) with a $p$ value (sig) of 0.001 , which is below 0.05 , which means that the family economy has a role in influencing early marriage in the hamlets of Penyenggir, Manggong and Batu Gapit.
\end{abstract}

Keywords: Social Life, Family Economy and Early Marriage

\title{
PENDAHULUAN
}

Penentuan batas minimum usia dalam perkawinan sangat penting karena secara tidak langsung mempengaruhi kualitas dalam kehidupan berumah tangga keluarga yang berkualitas akan melahirkan sebuah generasi yang lebih baik. Dikarenakan terciptanya kehidupan tentram, damai dan juga teratur adalah idaman untuk setiap orang. Begitu pula dalam kehidupan rumah tangga yang merupakan benteng pertama dan utama dalam menanggulangi permasalahan kehidupan di masyarakat dewasa ini. Karena berawal dari keluargalah permasalahan yang ada di masyarakat 
dapat terselesaikan dengan baik dan efektif, di samping itu keluarga merupakan bagian terkecil dari lingkungan masyarakat yang keduanya saling mempengaruhi serta keterkaitan satu sama lain.

Nusa tenggara Barat (NTB) tercatat sebagai provinsi dengan tingkat perkawinan muda (merariq kodek) yang cukup tinggi. Menurut data Kementrian Koordinator Pemberdayaan Manusia dan Kebudayaan (Kemenko PMK) Republik Indonesia, secara nasional NTB merupakan provinsi dengan tingkat perkawinan usia muda yang cukup tinggi yakni nomor 2 (dua) tertinggi setelah provinsi Gorontalo. Oleh karena itu, rekor ini dimaksudkan untuk mensinkronkan kebijakan - kebijakan dalam meningkatkan kepedulian semua pihak dalam upaya pendewasaan usia perkawinan di NTB. Berdasarkan data BKKBN NTB , 56, 7 persen pasangan usia subur menikah pada usia di bawah 21 tahun, pasangan dibawah umur di NTB paling banyak terjadi di kabupaten Lombok Timur kemudian Lombok Utara. Banyak faktor yang menyebabkan terjadinya pernikahan dibawah usia diantaranya faktor karena rasa cinta, faktor ekonomi, faktor dijodohkan, putus sekolah, dan hamil diluar nikah. (Kepala BKKBN Provinsi NTB, 2018)

Pada tahun 2016 Lembaga Perlindungan Anak (LPA) Kabupatem Lombok Timur (Lotim) menangani sebanyak 58 kasus pernikahan dini Lombok Timur sendiri memegang tingkat pernikahan dini tertinggi di NTB. Dari jumlah itu, terdapat ada tiga faktor utama penyebab terjadinya pernikahan dini, diantaranya faktor akibat putus sekolah, sudah dilakukannya hubungan biologis serta hamil diluar nikah. Dirincikannya, faktor alasan ekonomi yang berimplikasi pada putus sekolah sebanyak 25,3 persen, sudah melakukan hubungan bologi 33,3 persen, serta kehamilah yang terjadi diluar nikah atau tidak diinginkan sebanyak 41,6 persen. Terlebih lagi di desa Sikur Barat, sebagian besar masyarakat lebih memilih untuk menikah di usia dini (merariq kodek). Desa Sikur Barat memiliki 9 dusun dan kekadusan. Nama dusunnya antara lain : Endut, Montong Borok, Tengaing, Temanjor, Mentonggon, Jorong, Penyenggir, Manggong dan Batu Gapit dengan 
jumlah penduduk 2.254 dengan luas $1.36 \mathrm{~km}^{2}$. Prposal ini dibuat berangkat dari masalah, data sebagai berikut :

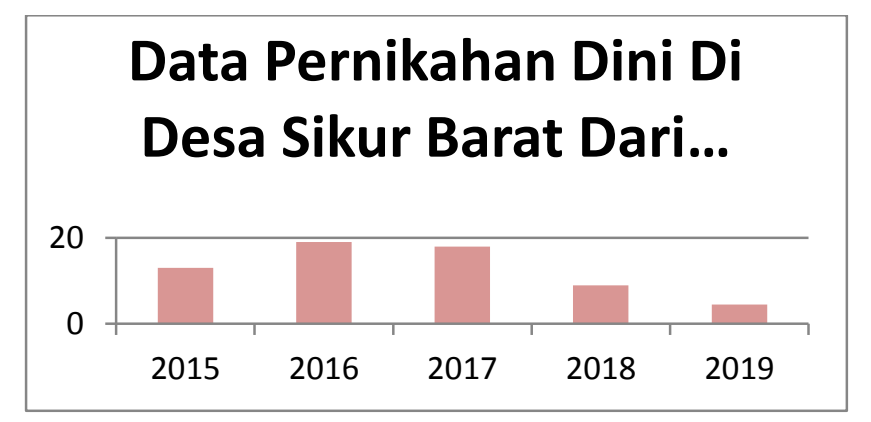

Gambar. 1

Setelah lulus SMA atau SMP mereka memilih untuk menikah, disebabkan faktor tidak bisa melanjutkan pendidikan dan lain sebagainya. Masalah yang sampai saat ini dihadapi oleh pemerintah indonesia terkait dengan pengangguran, jika banyak anak menikah diusia dini maka akan banyak sekali mencetak penganggurang yang bahkan belum bisa bekerja dan belum memiliki kemampuan/skill.

Konsep Pernikahan Dini

Definisi umur anak dalam Undang-undang (UU) Pemilu No.10 tahun 2008 (pasal 19, ayat 1) hingga berusia 17 tahun. Di Indonesia, menurut UU No 1/1974 tentang perkawinan, perempuan di atas usia 16 tahun diperbolehkan untuk menikah. Namun, UU Perlindungan Anak Tahun 2002 menetapkan bahwa siapa pun di bawah usia 18 tahun masih tergolong usia remaja.

Kehidupan Sosial

Konsep sosial adalah konsep keseharian yang digunakan untuk menunjuk sesuatu dan yang dipahami secara umum dalam masyarakat. Sedangkan konsep sosiologis merupakan konsep yang digunakan sosiologi untuk menunjuk sesuatu dalam konteks akademik. Sosiologi ialah suatu ilmu mengenai "das sein" dan bukan "das sollen". Sosiologi meneliti masyarakat serta perubahannya menurut keadaan kenyataan. Sehubungan dengan perkataan sosiolgi, perkataan sosial 
haruslah ditinjau sebagai semua kegiatan yang ada hubungannya dengan masyarakat luas, sesuai dengan perkataan asalnya "sozius" yang berarti "teman".

\section{Ekonomi Keluarga}

Keluarga merupakan lingkungan kelompok sosial terkecil, akan tetapi merupakan lingkungan yang paling dekat dengan anak. Sebagian besar anak dibesarkan oleh keluarga, disamping itu kenyataan menunjukkan bahwa di dalam keluargalah anak mendapatkan pendidikan dan pembinaan yang pertama kali. Keluarga merupakan lingkungan yang paling kuat didalam mendidik anak terutama bagi anak-anak yang masih belum memasuki bangku sekolah. Dengan demikian berarti seluk beluk kehidupan keluarga baik dari segi sosial ekonomi memiliki pengaruh yang paling mendasar dalam perkembangan anak.

\section{METODE PENELITIAN}

Metode penelitian yang digunakan adalah penelitian kuantitatif dengan pendekatan deskriftip, (Sugiyono, 2010) Tempat pelaksanaan penelitian ini adalah didusu Penyenggir, Manggong dan Batu Gapit desa Sikur Barat. Kecamatan Sikur. Pemilihan lokasi dilakukan secara sengaja (purposive) dengan pertimbangan bahwa banyak masyarakat desa Sikur Barat yang memilih untuk menikah di usia dini, ukuran sampel sebesar 30 orang yang menikah diusia dini didusun Penyenggir, Manggong, dan Batu Gapit.. Adapun tehnik pengumpulan data menggunakan , angket, observasi dan dokumentasi, dan di analisis menggunakan SPSS. 


\section{Uji Asumsi Klasik}

\section{1) Uji Normalitas Data}

Tabel 1. Hasil Pengujian Normalitas

\begin{tabular}{cccc}
\hline $\begin{array}{c}\text { Kolmogorove- } \\
\text { Smirnove }\end{array}$ & Asymp.Sig & Kriteria & Keterangan \\
\hline 0,700 & 0,710 & $>0,05$ & Berdistribusi normal \\
\hline
\end{tabular}

Sumber : Data Primer yang diolah, 2020

Berdasarkan Tabel diatas menunjukkan bahwa nilai yang dihasilkan pada Asym.sig sebesar 0,710 yang dapat dikatakan nilai asymp.sig 0,710 lebih besar daripada 0,05 maka dapat dikatakan data berditribusi normal.

\section{2) Uji Multikolinearitas}

Tabel 2. Hasil Pengujian Multikolinearitas

\begin{tabular}{cccc}
\hline Variabel & Tolerance & VIF & Keterangan \\
\hline Kehidupan & & & Tidak Terjadi \\
Sosial (X1) & 0,615 & 1,626 & Multikolinearitas \\
\hline Ekonomi & & & Tidak Terjadi \\
Keluarga (X2) & 0,615 & 1,626 & Multikolineartitas \\
\hline
\end{tabular}

\section{3) Uji Heterokedastisitas}

Tabel 3. Hsil Uji Heterokedastisitas

\begin{tabular}{cccc}
\hline Variabel & Thitung & Sig & Keterangan \\
\hline $\begin{array}{c}\text { Kehidupan } \\
\text { Sosial (X1) }\end{array}$ & $-1,748$ & 0,092 & Tidak Terjadi Heterokedastisitas \\
\hline $\begin{array}{c}\text { Ekonomi } \\
\text { Keluarga (X2) }\end{array}$ & 1,373 & 0,181 & Tidak Terjadi Heterokedastisitas \\
\hline Sumber : Data Primer yang diolah, 2020 &
\end{tabular}

Berdasarkan Tabel diatas menunjukkan bahwa pengujian ini menggunakan metode uji Glejser yang nilainya dilihat dari t sig. Pada 
variabel kehidupan sosial dan ekonomi keluarga memiliki nilai sig lebih besar daripada 0,05 maka dapat dikatakan data tidak terjadi heteroskedastisitas.

\section{Analisis Regresi Berganda}

Tabel 4. Hasil Uji Analisis Regresi Berganda

\begin{tabular}{ccc}
\hline Variabel & Koefisien B & Standar Error \\
\hline Konstanta & 7,742 & 4,019 \\
\hline Kehidupan Sosial (X1) & 1,694 & 0,373 \\
\hline Ekonomi Keluarga (X2) & 0,408 & 0,109
\end{tabular}

Sumber : Data Primer yang diolah, 2020

Berdasarkan tabel diatas menunjukkan koefisien ß merupakan bentuk sebuah persamaan regresi yang dapat dihasilkan sebagai berikut: $\mathrm{Y}=7,742+1,694 \mathrm{X} 1+0,408 \mathrm{X} 2+\mathrm{e}$

Persamaan regresi di atas dapat dijelaskan sebagai berikut:

1) Konstanta sebesar 7,742 ; artinya jika Kehidupan Sosial $\left(X_{1}\right)$ dan Ekonomi Keluarga $\left(\mathrm{X}_{2}\right)$ nilainya adalah 0 , maka Pernikahan Dini (Y') nilainya adalah 7,742

2) Koefisien regresi variabel Kehidupan sosial (X1) sebesar 1,694; artinya jika variabel independen lain nilainya tetap dan Kehidupan Sosial mengalami kenaikan 1\%, maka Pernikahan Dini (Y) akan mengalami kenaikan sebesar $1,694 \%$. Koefisien bernilai positif artinya terjadi hubungan positif antara Kehidupan Sosial dengan Pernikahan Dini, semakin naik Kehidupan Sosial maka semakin meningkat tingkat Pernikahan Dini.

3) Koefisien regresi variabel Ekonomi Keluarga $\left(\mathrm{X}_{2}\right)$ sebesar 0,408 ; artinya jika variabel independen lain nilainya tetap dan Ekonomi Keluarga mengalami kenaikan 1\%, maka Pernikahan Dini (Y) akan mengalami peningkatan sebesar $0,408 \%$. Koefisien bernilai positif artinya terjadi 
hubungan positif antara Ekonomi Keluarga dengan Pernikahan Dini, semakin naik Ekonomi Keluarga maka semakin meningkat Pernikahan Dini.

\section{Pengujian Hipotesis}

\section{1) Pengujian Signifikan (Uji T)}

Tabel 5. Hasil Uji T

Coefficients $^{\mathrm{a}}$

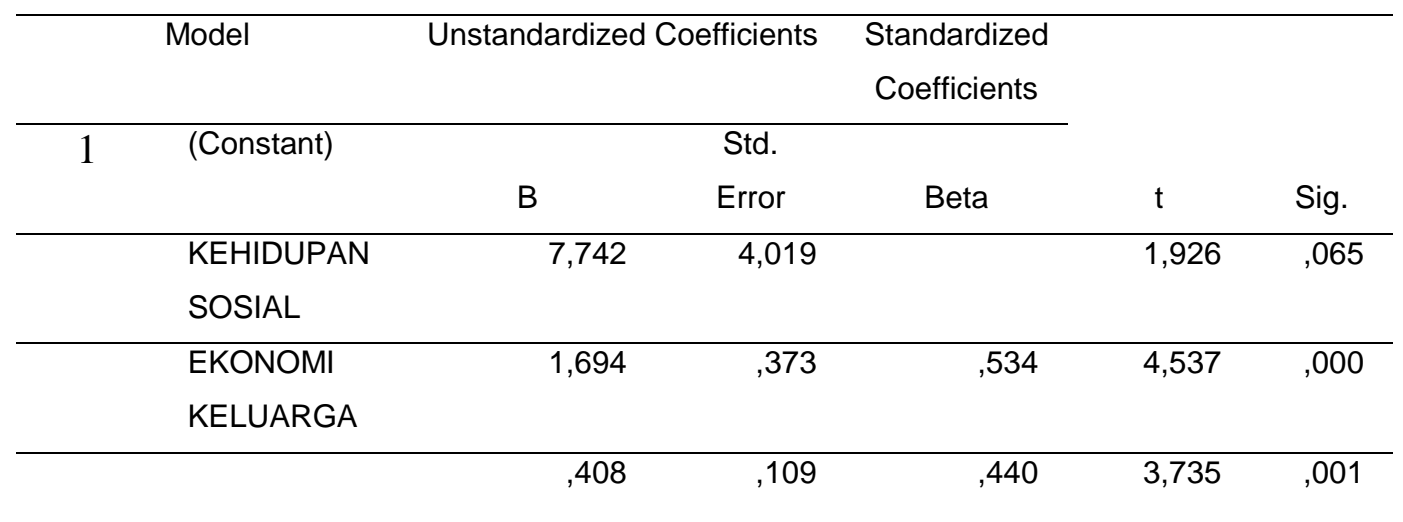

a. Dependent Variable: PERNIKAHAN DINI

Untuk memberikan interpretasi terhadap uji $\mathrm{t}$ dapat dijelaskan dibawah ini :

a. Berdasarkan nilai Signifikan

Nilai $\mathrm{t}$ hitung yang dihasilkan pada variabel kehidupan ekonomi adalah 4,537 dengan sig 0,000. Hasil analisis sig. $0,000<0,05$ maka H0 ditolak dan Ha diterima artinya secara individu variabel kehidupan sosial berpengaruh signifikan terhadap pernikahan dini. Nilai $\mathrm{t}$ hitung yang dihasilkan pada variabel ekonomi keluarga adalah 3,735 dengan sig 0,000. Hasil analisis sig. 0,001 <0,05 maka H0 ditolah dan Ha artinya secara individu variabel ekonomi keluarga berpengaruh signifikan terhadap pernikahan dini.

b. Perbandingan nilai $\mathrm{T}$ hitung dengan $\mathrm{T}$ tabel

Berdasarkan output SPSS diatas diketahui nilai $\mathrm{T}$ hitung variabel kehidupan sosial (X1) 4,537 sedangkan t tabel 2,051. Jika nilai t hitung 
$>$ maka ada pengaruh variabel bebas $(\mathrm{X})$ terhadap variabel terikat $(\mathrm{Y})$ atau hipotesis diterima. Yang artinya thitung 4,537 > t tabel 2,051 maka dapat disimpulan $\mathrm{H} 1$ atau hipotesis pertama diterima, ada pengaruh kehidupan sosial (X1) terhadap pernikahan dini di dusun Penyenggir, Manggong dan Batu Gapit. Variabel ekonomi keluarga (X2) t hitung 3,735 > t tabel 2,051 artinya ada pengaruh ekonomi keluarga (X2) terhadap pernikhan dini (Y) di dusun Penyenggir, Manggong dan Batu Gapit.

\section{2) Pengujian Simultan Model F (Uji F)}

Tabel 6. Hasil Uji F

\begin{tabular}{llrrrrr}
\hline \multicolumn{7}{c}{ ANOVA $^{\mathbf{b}}$} \\
Model & & Sum of Squares & Df & Mean Square & F & \multicolumn{1}{c}{ Sig. } \\
\hline 1 & Regression & 346,081 & 2 & 173,040 & 45,191 & ,000 $^{\text {a }}$ \\
\cline { 2 - 7 } & Residual & 103,386 & 27 & 3,829 & & \\
\cline { 2 - 7 } & Total & 449,467 & 29 & &
\end{tabular}

a. Predictors: (Constant), EKONOMI KELUARGA, KEHIDUPAN SOSIAL

b. Dependent Variable: PERNIKAHAN DINI

Dari hasil analisis uji F diatas, diketahui F hitung sebesar 45,191 dengan tingkat probabilitas 0,000 (signifikan). Nilai probabilitas lebih kecil dari 0,05 maka secara bersama - sama variabel kehidupan sosial dan ekonomi keluarga berpengaruh signifikan terhadap variabel pernikahan dini.

\section{3) Koefisien Determinan $\left(\mathbf{R}^{2}\right)$}

Tabel 7. Koefisien Determinan 


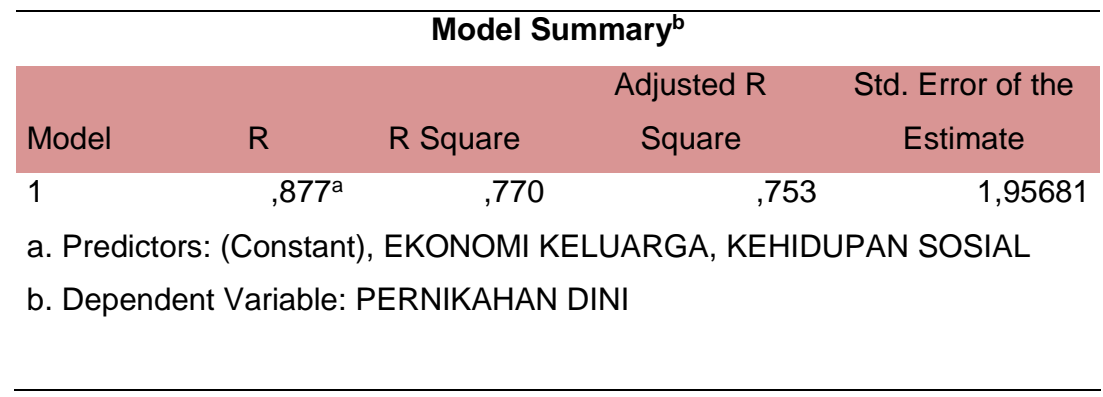

Koefisien determinasi $\left(\mathrm{R}^{2}\right)$ untuk mengukur kemampuan model dalam menerangkan variasi variabel dependen. Nilai $R^{2}$ adalah antara 0 dan 1 . Nilai $R^{2}$ yang kecil berarti kemampuan variabel - variabel bebas dalam mejelaskan variasi variabel terikat sangat terbatas. Nilai $\mathrm{R}$ square sebesar $0,753(75,3 \%)$ dapat diintepretasikan bahwa kemampuan model kehidupan sosial (X1) dan ekonomi keluarga (X2), menerangkan variasi variabel pernikahan dini (Y) sebesar 75,3\% dan sisanya dipengaruhi variabel independen lainnya sebesar $24,7 \%$.

\section{PEMBAHASAN}

Berdasarkan hasil pengujian dari hipotesis pertama menunjukkan adanya pengaruh positif dan signifikan antara kehidupan sosial terhadap pernikahan dini. Dari jawaban kuesioner (Angket) yang diisi oleh responden, warga dusun Penyenggir, Manggong dan Batu Gapit yang menikah dibawah umur 21 tahun. Ini menggambarkan bahwa semakin tinggi kehidupan sosial maka akan semakin tinggi pula tingkat pernikahan dini yang akan dilakukan oleh masyarakat. Hasil ini sesuai dengan penelitian (Nengsih, 2016), (Febriyanti \& Dewi, 2017), (Afriani, 2016), dan (Mahfudin \& Waqi'ah, 2016) yang menyatakan kehidupan sosial berpengaruh terhadap pernikahan dini (Maya, Andriani, \& Priyanti, 2019) menunjukkan bahwa faktor budaya dalam penelitian ini termasuk dorongan orang tua, dimana orang tua menjodohkan anaknya dengan kolega atau penduduk yang berdomisili satu wilayah. Hal ini disebabkan karena orang tua takut anaknya disebut sebagai perawan tua karena sebagian besar remaja khususnya remaja puteri menikah dibawah usia 20 tahun. 
Berdasarkan hasil pengujian dari hipotesis pertama menunjukkan adanya pengaruh positif dan signifikan antara ekonomi keluarga terhadap pernikahan dini. Dari jawaban kuesioner (Angket) yang diisi oleh responden, warga dusun Penyenggir, Manggong dan Batu Gapit yang menikah dibawah umur 21 tahun. Ini menggambarkan bahwa semakin tinggi ekonomi keluarga maka akan semakin tinggi pula tingkat pernikahan dini yang akan dilakukan oleh masyarakat. Hasil penelitian ini sesuai dengan penelitian Mubasyaroh (2016) kesulitan ekonomi menjadi salah satu faktor penyebab terjadinya pernikahan dini, keluarga yang mengalami kesulitan ekonomi akan cenderung menikahkan anaknya pada usia muda untuk melakukan pernikahan dini. Pernikahan ini diharapkan menjadi solusi bagi kesulitan ekonomi keluarga, dengan menikah diharapkan akan mengurangi beban ekonomi keluarga, sehingga akan sedikit dapat mengatasi kesulitan ekonomi.

\section{KESIMPULAN}

Dari data yang didapatkan dan dianalisis yang telah dilakukan dalam penelitian ini maka yang dapat disimpulkan adalah.

1). Hasil regresi dalam penelitian ini terbukti jika variabel Kehidupan Sosial (X1) dan variabel Kehidupan Sosial (X2) mempunyai pengaruh yang signifikan terhadap Pernikahan Dini (Y) didesa Sikur Barat. Hal tersebut ditunjukkan dengan hasil pengujian simultan F hitung Pernikahan Dini sebesar $(45,191)$ dengan tingkat probabilitas $(0,000)$ yang berarti secara bersama - sama Kehidupan Sosial dan Ekonomi Keluarga mempunyai andil dalam mempengaruhi Pernikahan Dini di dusun Penyenggir, Manggong dan Batu Gapit. 2). Dari uji signifikan juga terbukti jika masing - masing variabel independen juga berpengaruh signifikan terhadap variabel dependen. Variabel kehidupan sosial (X1) mempunyai pengaruh yang signifikan terhadap pernikahan dini didusun Penyenggir, Manggong dan Batu 
Gapit. Hal ini ditunjukkan dengan thitung (4,537) dengan p value (sig) 0,000 lebih kecil dari 0,05, berarti kehidupan sosial mempunyai andil dalam mempengaruhi pernikahan dini di desa Sikur Barat. Variabel ekonomi keluarga (X2) juga mempunyai pengaruh yang signifikan terhadap pernikahan dini di desa Sikur Barat. Hal ini ditunjukkan dengan t hitung $(3,735)$ dengan nilai $p$ value (sig) sebesar 0,001 berada dibawah 0,05 berarti ekonomi keluarga mempunyai andil dalam mempengaruhi pernikahan dini di dusun Penyenggir, Manggong dan Batu Gapit. 3). Nilai $\mathrm{R}$ square sebesar $0,753(75,3 \%)$ dapat diintepretasikan bahwa kemampuan model kehidupan sosial (X1) dan ekonomi keluarga (X2), menerangkan variasi variabel pernikahan dini (Y) sebesar 75,3\% dan sisanya dipengaruhi variabel independen lainnya sebesar $24,7 \%$.

\section{DAFTAR RUJUKAN}

Afriani, R. (2016). Analisis Dampak Pernikahan Dini pada Remaja Putri di Desa Sidoluhur Kecamatan Godean Yogyakarta. PROSIDING SEMINAR NASIONAL \& INTERNASIONAL, 1(1).

Febriyanti, N. P. V., \& Dewi, M. H. U. (2017). Pengaruh Faktor Sosial Ekonomi dan Demografi Terhadap Keputusan Perempuan Menikah Muda di Indonesia. PIRAMIDA, 13(2), 108-117.

Mahfudin, A., \& Waqi'ah, K. (2016). Pernikahan Dini dan Pengaruhnya terhadap Keluarga di Kabupaten Sumenep Jawa Timur. Jurnal Hukum Keluarga Islam, 1(1), 33-49.

Maya, R. A. A., Andriani, R., \& Priyanti, E. (2019). PENDIDIKAN KESEHATAN TENTANG DAMPAK PERNIKAHAN DINI TERHADAP KEHAMILAN REMAJA DI SMA NEGERI 14 PALEMBANG. Khidmah, 2(1), 10-18.

Nengsih, L. F. (2016). Dampak Pernikahan Dini Terhadap Kehidupan Sosial Ekonomi Keluarga (Studi Kasus di Desa Cisaat Kecamatan Dukupuntang Kabupaten Cirebon). IAIN Syekh Nurjati Cirebon.

Sugiyono, P. D. (2010). Metode penelitian pendidikan. Pendekatan Kuantitatif. 